Res Publica. Revista de Historia de las Ideas Políticas ISSN-e: 1989-6115

\title{
Política y trabajo: elementos para una reconstrucción de la crítica de Hannah Arendt a Marx
}

\author{
Borja Lucena Góngora*
}

Recibido: 05 de abril de 2018 / Aceptado: 14 de diciembre 2018

Resumen. El presente artículo procura articular el sentido que la filósofa Hanna Arendt localiza en la obra de Karl Marx, incidiendo en el lugar que ésta ocupa en la auto-comprensión e impulso de algunas de las tendencias en que se desplegó la moderna sociedad capitalista a partir de la ruptura decimonónica con los modelos políticos y sociales anteriores. Particularmente, se subraya la relación con el nuevo concepto de ser humano como animal laborans, la formulación marxiana de una nueva concepción del trabajo idónea para la inserción de aquél en las recién creadas estructuras de producción, así como las irradiaciones filosófico-políticas, en ese amplio marco, de la noción marxiana de "alienación" (Entfremdung, Entäusserung). Finalmente, se propone una valoración crítica de la aportación arendtiana a la comprensión del filósofo renano.

Palabras clave: Hannah Arendt; Marx; alienación; animal laborans; trabajo.

\section{[en] Work and Politics: Elements for the Reconstruction of Hannah Arendt's Criticicism of Marx}

\begin{abstract}
This article tries to appreciate the meaning of Hannah Arendt's critique of Marx, focusing on the way Marxian philosophy incardinates in the auto-comprehension of the modern capitalist society. In particular, it examines the new concept of human being as animal laborans, the Marxian formulation of a new conception of work suitable for the insertion men in the newly created structures of production, and the philosophical-political framework of the notion of "alienation" (Entfremdung, Entäusserung). Finally, a critical assessment of the Arendtian contribution to the understanding of the German philosopher is proposed.
\end{abstract}

Keywords: Hannah Arendt; Marx; Alienation; animal laborans, Work.

Sumario: 1. Karl Marx y el triunfo del animal laborans. 2. La confusión de trabajo y labor. 3. La alienación. 4. Evaluación crítica de la posición arendtiana en torno a Marx.

Cómo citar: Lucena Góngora, B. (2019). Política y trabajo: elementos para una reconstrucción de la crítica de Hannah Arendt a Marx, en Res Publica 22.1, 217-232

\footnotetext{
* lugongora@yahoo.es
} 
El que llega a Tecla poco ve de la ciudad, detrás de las empalizadas de tablas, los abrigos de arpillera, los andamios, las armazones metálicas (...). A la pregunta: -¿Por qué se hace tan larga la construcción de Tecla?- los habitantes, sin dejar de levantar cubos, de bajar plomadas, de mover de arriba a abajo largos pinceles -Para que no empiece la destrucción- responden.

Italo Calvino, Las ciudades invisibles.

\section{Karl Marx y el triunfo del animal laborans}

La obra filosófica de Hannah Arendt conservó durante todo su desarrollo un permanente interés por profundizar en la comprensión de unos pocos grandes filósofos, pensadores en torno a los cuales, de acuerdo con su interpretación, la tradición occidental de pensamiento filosófico y político había cristalizado. De la filosofía antigua, sin duda fue Platón el interlocutor privilegiado, por delante de Aristóteles; de la posterior, seguramente sea Marx quien reúne para ella el sentido propio de la filosofía política moderna, de su ascenso, su nueva visión de los asuntos humanos, y también de su crisis y disolución.

Marx fue el primer filósofo que, según Arendt, advirtió la capital transformación operada en la modernidad y la puso en el centro de la problemática filosófica y política. Esta verdadera transvaloración supuso que aquello que había sido considerado desde la Antigüedad el modo de actividad inferior de los seres humanos, es decir, el modo en el que están conducidos por las inmediatas urgencias de sus organismos, se convirtió en la actividad privilegiada y distintiva, imponiéndose al resto de actividades que los hombres son capaces de desarrollar en su existencia mundana. A esta actividad primaria, a este modo del aparecer de la vida activa humana, en tanto regulada por la lógica de la necesidad natural, Arendt la denominó "labor" (labor), estableciéndola como una de las tres formas posibles del "hacer" humano ${ }^{1}$.

\footnotetext{
El análisis de la acción y sus complejas derivas condujeron a Arendt a una reflexión extremadamente relevante acerca del lugar de lo político en la filosofía. En The Human Condition, la autora emprendió lo que puede entenderse como una fenomenología de la acción política, entregándose a la descripción de los modos de aparición del hombre en el ámbito del espacio público, así como a la distinción de los distintos tipos de actividades en los que se resuelve el "hacer" humano en relación a ese ámbito común de aparición. En esta obra ofrece una división tripartita que distingue grupos significativos de actividades: la labor, o aquel ámbito de conducta en el que los seres humanos se aseguran la pervivencia y conservación de las funciones orgánicas; el trabajo, o el tipo específico de "hacer" por el que el hombre se define como homo faber, constructor de un mundo de objetos; la acción, cuyo modelo de comprensión es la práxis tal y como la entendían los griegos, como un modo activo cuyo resultado no reside en un objeto externo al propio actuar, sino en el ejercicio o performance de la actividad misma. La fuente de la realidad política es esta última forma, la acción, unida íntimamente, según Arendt, al lenguaje como modo de aparición mutua. Cf. Arendt, H., The Human Condition, Chicago-London, The University of Chicago Press, 2005. (La condición humana, traducido por Gil Novales, R., Barcelona, Paidós, 2005). "Trabajo" (Arbeit) es el término genérico utilizado por Marx, que no realiza distinción entre "labor" (labor) y "trabajo" (work), como sí hace Arendt. Para evitar la confusión, al referirnos al uso marxiano del concepto de trabajo lo entrecomillaremos ("trabajo"), mientras que en su uso propiamente arendtiano lo verteremos sin añadido ninguno. Dada la casi estricta correspondencia que, para Arendt, presentan, en lo que sigue también utilizaremos el término "fabricación" para nombrar el trabajo arendtiano.
} 
De acuerdo con la genealogía arendtiana de las ideas políticas, en el marco de las categorías antropológicas de la Antigüedad, la labor señalaba el lugar en el que la actividad humana se hermanaba de modo más íntimo con las exigencias de la naturaleza, con las demandas inexorables a las que responden la totalidad de los organismos vivos. La labor era situada, entonces, en el punto de convergencia de lo animal y lo humano, y revelaba el hacer que hacía indistinguible al animal humano del resto de los organismos. Por esta razón, la labor fue depreciada hasta ocupar la base inferior y abyecta de un vivir humano disparado "hacia arriba", hacia las actividades que introducen la grieta insalvable que separa la vida meramente animal de la humana: la fabricación y, sobre todo, la política ${ }^{2}$. En este sentido, Arendt señala que Aristóteles situó a la labor, esa reunión de las ocupaciones "en las que el cuerpo más se deteriora", en el lugar más bajo de la jerarquía de las actividades ${ }^{3}$.

No obstante lo anterior, la filosofía de Platón había ya supuesto, antes de Aristóteles, el principio de una radical re-categorización de las actividades humanas, reducidas en principio a ser lo otro indiferenciado con respecto a la verdadera "actividad": la contemplación, el pensar filosófico tal y como el pensador ateniense lo acuñó e introdujo en la tradición occidental. De este modo, en el marco de las categorías platónicas, se instauró un marco de degradación de toda la esfera de las actividades humanas, que fueron así absorbidas y asimiladas principalmente a las características de una sola, la más básica y literalmente necesaria: la labor. Al mismo tiempo, el pensamiento filosófico se afirmaba como única y verdadera "actividad" humana. Por su parte, la época moderna, como acertadamente supo distinguir Marx, fue el momento en el que el hombre, reducidas de aquella manera las actividades y borrada de su horizonte la "actividad" contemplativa, quedó fijado únicamente como animal laborans, como criatura sólo interesada en aquellas actividades que aseguraban la satisfacción de las necesidades biológicas y fisiológicas inextirpables: un ser sólo caracterizado por la incesante repetición de los ciclos de elaboración y consumo.

El servicio de Marx a la comprensión de los tiempos modernos, aquello que revela su gran perspicacia filosófica, es, de acuerdo con Arendt, haber sabido comprender la nueva organización del hacer humano en torno a los requerimientos de la labor, haber señalado que ese sería el gran problema de la vida en condiciones modernas, y haber revolucionado la tradición de pensamiento para hacer posible la inclusión de este hecho decisivo en la aprehensión filosófica de la vida humana; sin embargo, y al mismo tiempo, su incapacidad para escapar a las redes de esa misma tradición, su encadenamiento a las ideas y categorías clave del pensamiento filosófico y la teoría política tradicionales, supuso que no pudiera ofrecer una respuesta desligada de las supuestos de la tradición, aunque reformulara sus conceptos o los moldeara de acuerdo con nuevas necesidades y sometiéndolos a desplazamientos de gran intensidad. El modo en que Marx trató de escapar a la tradición fue la peraltación extremada de algunos de sus rasgos, y, en este caso, pasó por rasgar el velo que ocultaba la nueva realidad moderna, la labor, extendiéndose a través de la exposición y clarificación de su lugar central en la vida humana y la descripción de un nuevo marco de conocimiento capaz de dar cuenta de lo que ya estaba ocurriendo en la realidad: el auge del animal laborans ${ }^{4}$.

Cf. "Labor", en H. Arendt, La condición humana, op. cit., pp. 107- 163.

H. Arendt, La condición humana, op. cit., p. 109.

4 En esta medida, el pensamiento de Marx no deja de cumplir, según la perspectiva arendtiana, las previsiones de 
De acuerdo con lo anterior, en Marx encontramos un detallado programa de la Modernidad, un proyecto filosófico que pugna por desligarse de los "prejuicios" morales, religiosos o políticos que todavía la tradición anterior observaba y que, según el filósofo de Tréveris, obstaculizaban el reconocimiento pleno del ser humano como dimensión específica de la naturaleza laborante. Esa es, sin duda, una de las grandes críticas de Marx a la burguesía: no querer reconocer hasta sus últimas consecuencias el proceso puesto en funcionamiento una vez derrocados los regímenes medievales, $\mathrm{y}$, por tanto, intentar aminorar o postergar la transición a la nueva realidad del homo laborans a través de subterfugios moralizantes o ilusiones ideológicas consoladoras, tratar de detener el autónomo despliegue de las fuerzas productivas ${ }^{5}$. En definitiva, Marx fue el filósofo que, según la pensadora judía, situó al pensamiento filosófico en la nueva realidad material que había sido revolucionada por los acontecimientos modernos y la inauguración de la era industrial, el pensador que acometió la sutura de una herida abierta en el principio de la Modernidad y que había distanciado cada vez más el mundo vivido de su aprehensión filosófica. Con ello, cumplió su proyecto de aunar en un sólo torrente el pensamiento y los procesos materiales en el seno de los que emerge, plasmar "el devenir filosofía del mundo y el devenir mundo de la filosofía"6.

Arendt describe en La condición humana cómo la labor se extendió a lo largo de la época moderna hasta cubrir la práctica totalidad de la vida humana occidental. El trabajo, entendido en sentido arendtiano, fue siendo desplazado en tanto la nueva época ya no demandaba la construcción de un mundo estable y dador de espacio, sino el incremento de la riqueza a través de la constante elaboración del entorno y la base materiales de la sociedad. Las cosas creadas como fruto del trabajo, las cosas fabricadas para durar y apuntalar las lindes de un mundo, fueron apartadas en favor de los flujos de riqueza, la constante multiplicación de los excedentes, la acumulación de capital fluido y en constante movimiento y transformación; lo estable fue corroído por la multiplicación de maniobras de expolio material de lo mundano, disuelto en los procesos económicos de acumulación; el mundo perdió su consistencia al ser movilizado como materia prima al servicio de la abundancia en el consumo; todo el mundo de la fabricación y el trabajo fue asimilado por los procesos indefinidos de elaboración y dispendio que caracterizan la economía de los cuerpos y los organismos vivos. Arendt, en suma, al describir el auge de la sociedad moderna, realiza un vivo cuadro de su carácter líquido ${ }^{7}$, por utilizar la expresión del sociólogo Baumann, un gran fresco en el que se exhiben líneas fundamentales de comprensión de la sociedad global actual ya expuestas con claridad por el mismo Marx: todo lo sólido

Hegel, para quien la filosofía "siempre llega demasiado tarde" y no puede más que comprender lo ya sucedido. A pesar de las aspiraciones declaradas por Marx, Arendt localiza en su filosofía, no la apuesta por una nueva realidad aún inexistente, sino un programa que recoge lo que ya estaba pasando en la sociedad industrial.

5 El énfasis en eliminar los obstáculos que entorpecen el desarrollo de las fuerzas productivas es fundamental en el pensamiento posterior de cuño marxista: "La gran industria, liberada de las trabas de la propiedad privada, se desarrollará en tales proporciones que, comparado con ellas, su estado actual parecerá tan mezquino como la manufactura al lado de la gran industria moderna". F. Engels, "Principios del comunismo", en F. Engels y K. Marx, El manifiesto del partido comunista, traducido por Editorial Progreso, Barcelona, L'Eina Editorial, 1989, p. 89 .

6 K. Marx, Introducción a la crítica de la filosofia del derecho de Hegel, traducido por Ripalda, J.M., Valencia, Pre-textos, 2013, p. 28.

7 Cf. "La derrota del homo faber y el principio de felicidad", "La vida como bien supremo", "La victoria del animal laborans", en: Arendt, H., La condición humana, op. cit., pp. 324-341. 
se desvanece en el aire ${ }^{8}$. No obstante, lo peculiar del filosofar marxiano, expresado como protesta, se encuentra en la aceptación de los procesos esenciales que otorgan su semblante a la sociedad moderna; para él, estos procesos, a pesar de su inusitada violencia y su plasmación traumática en la transición de la vieja a la nueva sociedad, revelan el proyecto humano en su verdad y anuncian una definitiva reconciliación del hombre con un mundo que momentáneamente se le aparece como ajeno.

La Modernidad, según Marx, ha situado al hombre en la coyuntura de su real entidad, lo ha arrojado a la condición desnuda de ser laborante, y sobre esa base irrenunciable ha de levantarse una sociedad en la que se vean canceladas todas la contradicciones que han soportado las sociedades (pre)históricas: “(...) el modo capitalista de producción se presenta $(\ldots)$ como necesidad histórica para la transformación del proceso de trabajo en un proceso social (...)" .

\section{La confusión de trabajo y labor}

Así pues, Marx pone en el foco de la problemática moderna la revelación del ser humano como animal laborans. El "trabajo", de acuerdo con él, señala la actividad que integra plenamente al hombre en la naturaleza y revela la consistencia misma de lo humano; es lo que define la condición humana y la sujeta a la tierra y al conjunto de sus procesos naturales.

La historia misma es una parte real de la historia natural, del desarrollo de la naturaleza en el hombre (...) La ciencia natural comprenderá algún día la ciencia del hombre (...) serán una sola ciencia ${ }^{10}$.

8 La coincidencia estructural del capitalismo y los procesos puramente biológicos puede adivinarse en la caracterización hegeliana de la vida: "fluidez universal". Hegel, G.W.F, Fenomenología del espiritu, edición bilingüe de Antonio Gómez Ramos, Madrid, Abada-UAM, 2010, p. 249.

9 Marx, K., El capital, traducido por Scaron, P. Buenos Aires- México D.F- Madrid, Siglo XXI, 1975, p. 407.

10 K. Marx y E. Fromm, Marx y su concepto del hombre. Manuscritos económico-filosóficos, III, traducido por Campos, J., México D. F., Fondo de Cultura Económica, 1962, p. 145. Cabe subrayar que Arendt no realiza distinción alguna entre los escritos publicados efectivamente por Marx y aquellos que, inéditos a su muerte, fueron publicados más adelante por marxistas como Engels, Kautsky o Riazanov. Esta indistinción daña en algunos aspectos a la consistencia de su crítica, pero, dado que nuestra intención es dar cuenta de ésta, utilizaremos tanto los textos publicados por Marx como los sólo dados a la imprenta tras su muerte. Por otro lado, Arendt tampoco advierte una ruptura epistemológica en la obra de Marx, al modo en el que Althusser la advirtió. De acuerdo con éste, después de sus obras juveniles, Marx rompió con el hegelianismo y con toda teoría fundada en la "esencia del hombre". Con respecto a Hegel, se separó radicalmente de la forma particular de la dialéctica hegeliana para desarrollar una forma "racional" de dialéctica. El filósofo francés critica la visión predominante de la dialéctica marxista como simple "inversión" de la hegeliana; según esta comprensión, argumenta, el papel determinante de la "idea" con respecto a la base material en Hegel es sustituido por la determinación inversa de la idea por la base material en el filósofo de Tréveris; sin embargo, afirma el pensador francés, en Marx no existe un simple cambio de lugar de los términos dialécticos, sino que "son a la vez los términos y su relación lo que cambia de naturaleza y de sentido". "Contradicción y sobredeterminación", en L. Althusser, La revolución teórica de Marx, traducido por Harnecker, M., México - Buenos Aires, Siglo XXI Editores, 2004, pp. 71-106, aquí p. 89. Arendt, al contrario que Althusser, lee en el itinerario entero del filósofo renano una continuidad sustancial que emparenta sus primeros escritos con El capital, aun admitiendo la renuncia a ciertos conceptos heredados de la comprensión hegeliana. Esta lectura, a la que no cabe despojar de algunos problemas apuntados por Althusser con respecto a posiciones similares, no nos parece, sin embargo, desechable sin más, sobre todo si atendemos a la fidelidad de Marx a la concepción del "trabajo" como "metabolismo con la naturaleza" (Cf. Notas 18 y 51). En el interés por hallar comprensión a los fundamentos de la crítica arendtiana, el presente trabajo prescinde también del corte epistemológico propuesto por Althusser. 
De acuerdo con Arendt, Marx conservará hasta el final de sus días la convicción de que con el "trabajo", el hombre se sitúa en una realidad natural que fue filosóficamente desatendida en razón de la postulación de un pretendido carácter espiritual del alma y las facultades "superiores". El hombre, en su intercambio material con la naturaleza, es reintroducido por su propio quicio al fundamento de su humanidad. El "trabajo", por lo tanto, lo devuelve al marco natural, que es el único que posee realidad determinada, pero, en tanto lo sitúa en ese marco y lo determina como real, lo distingue a su vez del resto de los seres naturales ${ }^{11}$. Es por eso por lo que Arendt subraya la revolucionaria tesis marxiana de que el hombre, a través del "trabajo", se crea a sí mismo y no debe su existencia a otro ser exterior a él, como Dios, sino a su propia actividad laborante ${ }^{12}$. En este sentido, tal y como lo interpreta la pensadora judía, Marx puede alcanzar tesis centrales de su pensamiento: "el ser determina la conciencia"13 quiere decir propiamente que es el "trabajo" aquello que introduce a los hombres en el trato con lo real, lo que funda su aparición como efecto real $-\mathrm{y}$ no como "causa espiritual" ilusoria- en el campo de fuerzas de la naturaleza omnicomprensiva; quiere decir, por lo tanto, en términos arendtianos, que la labor constituye la plataforma sobre la que se levanta la existencia humana.

En la tesis de que el "ser" determina la conciencia es posible localizar, según defiende Arendt, la crucial confusión que señala a Marx no sólo como culminador de una tradición que desprecia el carácter peculiar de la acción, sino también como presentimiento de la absorción de toda manifestación humana por los procesos laborantes automáticos conformadores de la sociedad contemporánea $\mathrm{y}$, en última instancia, de los sistemas totalitarios. En La condición humana, Arendt se demora en el significado de la filosofía de Marx para la sociedad contemporánea. El capítulo titulado "labor" se abre con un aviso: "En este capítulo se critica a Karl Marx"14. Desde su perspectiva, Marx acompaña con su pensar a los procesos sociales desatados en la Modernidad, asegurando conceptualmente el anegamiento de toda expresión del carácter activo del hombre por parte de la labor, la actividad aseguradora de la vida y mantenedora de las estructuras inequívocas de la supervivencia biológica; así como en el sistema de la sociedad moderna "toda actividad que no es necesaria para la vida del individuo o para el proceso de la vida de la sociedad se clasifica en la categoría

11 Recordemos cómo, en Spinoza o Hegel, “omnis determinatio est negatio". Marx determina la específica entidad humana en relación, no en la posesión de capacidades distintas, sino a la productividad de su "trabajo", que desemboca en que el propio laborante crea todo un " mundo" adecuado a sus necesidades y, de la misma manera, se crea a sí mismo en el proceso de producción; no son el pensamiento o la conciencia lo que establece distinción entre el animal y el hombre, pero sí la producción por parte de éste de sus propias condiciones materiales de vida: "Lo que son coincide, por consiguiente, con su producción, tanto con lo que producen como con el modo como lo producen”. F. Engels y K. Marx, La ideología alemana, traducido por Roces, W., Barcelona, Ediciones Grijalbo, 1970, p. 35.

12 Cf. "El desafío moderno a la tradición", en H. Arendt, Karl Marx y la tradición del pensamiento político occidental, traducido por Serrano de Haro, A., Madrid, Ediciones Encuentro, 2007, p. 30 y ss. En un escrito posterior, la filósofa aclara cómo esta rotunda tesis constituye una rebelión contra la propia facticidad de la condición humana, que determina que, ya sea desde el punto de vista del individuo, ya desde el de la especie, el ser humano nunca se debe su existencia a sí mismo. Cf. “On Violence”, en: Arendt, H., Crises of the Republic, San Diego - New York - London, Harcourt Brace \& Company, 1972, p. 115.

13 "No es la conciencia de los hombres lo que determina su ser, sino, por el contrario, es su existencia social lo que determina su conciencia". "Prólogo", en K. Marx, Contribución a la crítica de la economía política, traducido por Tula, J., Mames, L., Scaron, P., Murmis, M. y Aricó, J., Buenos Aires - México D. F. - Madrid, Siglo XXI Editores, 2008, p. 5.

14 H. Arendt, La condición humana, op. cit., p. 107. 
de la mera diversión"15, para el filósofo alemán todo aquello que no se plasma en la elaboración y consumo de la materia por parte de una sociedad organizada no constituye otra cosa que una ilusión, una actividad vacía y carente de contenido propio, por lo que la "moral, la religión, la metafísica y cualquier otra ideología y las formas de conciencia que a ellas corresponden pierden, así, la apariencia de su propia sustantividad"16. Aunque Marx cifre el centro del comportamiento humano como "trabajo", las características distintivas de éste, de acuerdo con la interpretación de Arendt, nos hablan de una entrega casi sin resto a la labor. Marx, siguiendo la tendencia de los pensadores modernos, tendió a "considerar toda labor como trabajo" 17 , a transferir el prestigio productivo del homo faber al animal laborans. En efecto, el "trabajo" es, de acuerdo con la categorización de Marx, no otra cosa que el metabolismo del hombre con la naturaleza ${ }^{18}$, es decir, la actividad de los cuerpos involucrados en el cumplimiento de las exigencias orgánicas; es, por lo tanto, aquello que Arendt nombró como "labor" y distinguió nítidamente del trabajo o fabricación. Producto de esta crucial confusión, Marx puede afirmar: "La fuerza de trabajo es, ante todo, materia natural transformada en organismo humano" 19 .

La pensadora de Hannover adivina en la transformación semántica del concepto de "trabajo" una nuclear apuesta filosófica por reformular la condición humana en torno a un nuevo polo significativo, y escoge el pasaje arriba transcrito de El capital, en el que se expone con claridad esta nueva posición: esta actividad no tiene como fin producir un mundo de objetos destinado a durar, de delimitaciones que abran un espacio en el que actuar, sino confeccionar cuasi-objetos elaborados con el sólo propósito de ser deglutidos e incorporados por los organismos en sus pulsiones metabólicas; no produce mundo, pero reproduce la vida; no fabrica cosas, sino valores ${ }^{20}$. El mundo del "trabajo", tal y como Marx lo representa, es, precisamente, el lugar de la total licuefacción de lo sólido, del reblandecimiento de los contornos del mundo. El verdadero reino de la "fluidez universal".

\section{La alienación}

Es en la labor, según Arendt, donde deposita Marx la actividad de apropiación del mundo por parte del hombre, la anulación de la distancia que, separando a los objetos constituidos del sujeto productor, describe la alienación como separación del hombre y su propia esencia productora. Es así como la pensadora alemana se introduce en la crítica de la teoría marxiana de la alienación (Entfremdung, Entäusserung), que, según su perspectiva, está afectada de una focalización extrema en la búsqueda de

\footnotetext{
Ibidem, p. 142.

F. Engels y K. Marx, La ideología alemana, op. cit., p. 26.

H. Arendt, La condición humana, op. cit., p. 112.

18 "Como trabajo útil, pues, el trabajo es, independientemente de todas las formaciones sociales, condición de la existencia humana, necesidad natural y eterna de mediar el metabolismo que se da entre el hombre y la naturaleza (...)" K. Marx, El capital, I, op. cit., p. 53.

20 "Corresponde al trabajo vivo apoderarse de esas cosas, despertarlas del mundo de los muertos, transformarlas de valores de uso potenciales a valores de uso efectivos y operantes (...) su contacto con el trabajo vivo, es el único medio para conservar y realizar como valores de uso dichos productos del trabajo pretérito". Ibidem, p. 222 .
}

19 Ibidem, p. 261. 
la completitud del sujeto humano, en menoscabo de la realidad del mundo. Marx, de acuerdo con ella, compartió la preocupación unilateral del pensamiento moderno por el sujeto, considerando el "mundo" únicamente como material de realización de la humanidad o reserva de elementos inertes subordinados a los proyectos de la voluntad, de modo que tenía forzosamente que participar en la incomprensión general de la filosofía moderna hacia la política, que es primariamente preocupación por el mundo, no por el sujeto. Tal y como la comprendió Arendt, la alienación moderna del mundo, el despojamiento de la realidad común constitutiva de un marco de existencia para los sujetos ${ }^{21}$, fue contestada desde el pensamiento de Marx como una protesta ante la separación del hombre con respecto al mundo, y por la postulación de la absorción de éste en la actividad humana, que vendría a significar la completa reunión del hombre con su propia esencia.

(...) lo que crea el comunismo, es precisamente la base real para hacer imposible cuanto existe independientemente de los individuos, en cuanto este algo existente no es, sin embargo, otra cosa que un producto del intercambio anterior de los individuos mismos ${ }^{22}$.

La conciencia del desgarramiento del hombre y del mundo tomó en Marx, de acuerdo con el análisis arendtiano, una forma ya ensayada en el idealismo alemán: la de una crítica general de la separación sujeto-objeto y la búsqueda de una posición subjetiva carente de grietas, capaz de asumir en su plenitud toda la realidad. Tomó una forma contundentemente filosófica y modulada por la naturaleza laborante que Marx postulaba en el ser humano. De este modo, la reconciliación con el mundo fue propugnada desde su pensamiento como una asunción de toda realidad material exterior por parte de los procesos de la labor, como una anulación de la independencia de lo mundano a través de las actividades metabólicas de los organismos, como una colonización de todo el espacio de lo real por parte de la racionalidad laborante.

El reflejo religioso del mundo real únicamente podrá desvanecerse cuando las circunstancias de la vida práctica, cotidiana, representen para los hombres, día a día, relaciones diáfanamente racionales, entre ellos y con la naturaleza. La figura del proceso social de la vida, esto es, del proceso material de producción, sólo perderá

21 El hombre moderno, separado de sus semejantes en el plano de la acción, pero fundido con ellos en el de los procesos imparables de la vida biológica, asistió a lo que la filósofa denomina una creciente "alienación del mundo". Esta expresión, que evoca al concepto de "alienación” formulado por Marx, supone realmente una posición polémica de la autora con respecto a éste, y tanto que dibuja una frontera adversativa clara entre los dos. Mientras la alienación en Marx refiere a la relación del sujeto consigo, a la separación con respecto a su propia esencia y su estado de pérdida en el mundo objetivo, en Arendt tiene que ver con la pérdida por parte del hombre moderno de su hogar mundano, su incapacidad para habitar políticamente el mundo. Así, mientras la solución a la alienación marxiana consistiría en convertir en "sujeto" al mundo objetivo a través del trabajo, porque sólo así el hombre reencontraría su propia mismidad, la de la pensadora judía pasaría precisamente por lo contrario: asegurar la alteridad del mundo, fortalecer los límites y medidas que impidan que sea asumido por el sujeto como parte de su propio organismo, afirmarlo en su "carácter de cosa". Cf. "La vita activa y la época moderna", en H. Arendt, La condición humana, op. cit., pp. 277-355. Es importante reiterar que, de acuerdo con Arendt, la problemática de la alienación no constituyó una preocupación exclusiva del "joven” Marx, sino el significado crucial que recorre toda su obra.

22 F. Engels y K. Marx, La ideología alemana, op. cit., p. 82. 
su místico velo neblinoso cuando, como producto de hombres libremente asociados, éstos la hayan sometido a su control planificado y consciente ${ }^{23}$.

El hombre, según esto, se encuentra "en casa en el mundo" no cuando meramente lo "comprende" en el pensamiento, sino cuando moviliza su materia de acuerdo con las exigencias metabólicas de la vida humana, cuando hace de la realidad "objetiva" sólo un momento de la organización vital de la sociedad humana. Marx, por lo tanto, no sólo describe la labor como esencia de la humanidad, sino que, además, la contempla como una promesa salvífica de redención, le atribuye la función soteriológica que Hegel había depositado en la capacidad de pensar religiosa y, sobre todo, filosóficamente. Lo que despoja al mundo de su extrañeza, según Marx, es la inserción en los procesos regulados por las necesidades del organismo humano, la puesta en movimiento de lo aparentemente sólido y ajeno a efectos de su asimilación por el cuerpo, la transformación incesante de la materia en relación con los requerimientos de los organismos humanos laborantes. Por esta razón, la labor filosófica, según Marx, no es sólo la de interpretar, sino, sobre todo, la de transformar la realidad. El objeto de esta transformación es superar las posturas insatisfactorias del idealismo y el materialismo dominantes hasta Hegel y Feuerbach, someter la aparente indocilidad del mundo y la naturaleza al carácter activo-laborante del hombre, llegar a concebir "lo sensorial como actividad sensorial-humana práctica" 24 . Producir, en el sentido laborante que le presta Marx, es adueñarse humanamente del mundo, hacer del "espanto del mundo objetivo" una realidad propia y familiar, cancelar la subordinación del sujeto a un mundo ajeno, indómito e independiente de sus necesidades y anhelos. Es, en suma, realizar verdaderamente la filosofía llevando la aparente realidad objetiva, independiente, extraña, a su esencial condición de actividad humana transitoriamente "objetivada".

Arendt subraya el hegelianismo implícito en la concepción marxiana de la alienación y de su superación. Marx, según ella, no hace otra cosa que intensificar el movimiento hegeliano de asimilación de toda realidad objetiva por parte del espíritu humano, pero prestando a todo el movimiento una forma materialista plenamente integrada en los procesos de transformación iniciados por la Modernidad. El mismo impulso originario existe por igual en ambos pensadores: el movimiento hacia la sutura de toda escisión en la realidad, la voluntad entregada a soldar entre sí los fragmentos separados de la existencia humana, el deseo de restitución de la vida aislada y desorientada a una totalidad omnicomprensiva y plena de sentido. Kolakowski lo denominó el "mito de la autoidentidad humana", y lo ha descrito, en su forma marxiana, como el anhelo de una realización de la identidad entre sociedad y política, es decir, de abolir definitivamente la dicotomía y la contradicción que separan la existencia personal y la colectiva ${ }^{25}$. Así como en Hegel la Aufhebung de las grietas existenciales de la vida humana se ofrece en la forma de una apropiación de la realidad por parte del pensamiento, que adquiere así la forma de un metabolismo

23 K. Marx, El capital, I, op. cit., p. 97.

24 “Tesis sobre Feuerbach", V, en F. Engels y K. Marx, La ideología alemana, op. cit., p. 667.

25 Cf. L. Kolakowski, “The Myth of Human Self-Identity”, en L. Kolakowski y S. Hampshire (eds.), The Socialist Idea, Great Britain, University of Reading, 1974, especialmente pp. 18-26. El autor polaco, en este ensayo, señala una vía de comprensión ampliamente presente en los estudios de Arendt: más allá de la intención del proyecto de Marx, la posibilidad de realización de una reconciliación plena de sociedad civil y Estado no parece factible si no es a través de una forma totalitaria de Estado. Ibidem, p. 26. 
espiritual que asimila el ámbito del ser como si de un vasto proceso digestivo se tra$\operatorname{tara}^{26}$, en Marx ese metabolismo es devuelto a su lugar originario, al organismo vivo asimilador, la "fábrica" del cuerpo humano que, al auto-producirse sin descanso, transforma decisivamente la materia del mundo convirtiéndolo en "sí mismo", en realidad donde el existir humano, lejos de perderse, puede reconocerse como sujeto.

(...) con la constitución de la actividad individual como directamente universal, es decir, actividad social, los momentos objetivos de la producción se verán libres de esta forma de alienación; se constituirán como propiedad, como el cuerpo orgánico de la sociedad en el que los individuos se producen a sí mismos como individuos, pero como individuos sociales ${ }^{27}$.

La absorción del mundo por las funciones laborantes de los cuerpos rectifica, a su vez, la problemática inherente a la fabricación de objetos duraderos, señalada por Arendt al tratar de la noción de trabajo: en éste, el objeto se despega del organismo productor, se establece en el mundo ocupando una posición autónoma con respecto al artesano, y pasa a formar parte de un orden de cosas que obedece a sus propias leyes. Tal es, de acuerdo con la interpretación de la autora, el problema esencial de la alienación tal y como se presenta en Marx. En la fabricación, el hombre se aliena de su producto, por lo que sería preciso ingeniar formas de "fabricación" no condicionadas por la naturaleza "objetiva" de sus productos, formas de fabricación que incorporaran el poder asimilador de la labor. La labor, en este marco marxiano, aparece como único antídoto válido ante el carácter cosificador del trabajo. Por otra parte, es también una realidad que el objeto ya fabricado pasa irremisiblemente a pertenecer a las leyes implacables del tiempo, es decir: de la erosión, el desgaste, la corrupción, que significan en el cuerpo del objeto la amenaza de la muerte futura. La labor, al incluir las cosas en el torrente indiferenciado de la vida, anula las leyes extrañas y alienantes de la realidad; al movilizar la materia, al no dejar que cristalice en objetos dejados al albur del uso y del tiempo, otorga a lo real una carta de eternidad, de ahí que los procesos de la vida aparezcan como eternos y recurrentes. En rigor, en la labor no existe la destrucción, como sí existe en la fabricación de objetos; el material integrado en el movimiento metabólico del cuerpo social, al no llegar nunca a constituir objeto autónomo alguno, no contempla el aniquilamiento de nada constituido. La “destrucción” presente en el sistema metabólico no es más que el reverso

26 Son numerosos los pasajes en los que diversos intérpretes han subrayado la naturaleza metabólica del espíritu hegeliano. Hegel mismo lo expresa con rotundidad: "En efecto, lo mecánico es ajeno al espíritu, que tiene interés en ingerir el alimento indigesto que le ha llegado, es decir, en comprender y apropiarse lo que en él todavía está desprovisto de vida". Citado en K. Löwith, De Hegel a Nietzsche. La quiebra revolucionaria del pensamiento en el siglo XIX, traducido por Estiú, E., Buenos Aires, Katz Editores, 2008, p. 380. Löwith también cita al joven Hegel de los escritos teológicos, donde presenta una sugerente imagen del acto espiritual de apropiación de lo objetivo en la eucaristía: "Ese «amor que se ha objetivado y lo subjetivo que se ha convertido en cosa (...) se vuelve a subjetivar en el acto de comer». Por tanto, si el espíritu es realmente viviente en el disfrute del pan y del vino, «desaparecen» los objetos en su mera objetividad enfrentada al sujeto". Ibidem, p. 422. Ricoeur ha señalado, de manera semejante, la mismidad de los procesos asimilatorios de la realidad presentes en Hegel y en Marx, sólo que con carácter espiritual en aquél, materialista en éste: Cf. P. Ricoeur, Ideología y utopía, traducido por Bixio, A.L., Barcelona, Gedisa, 1989, p. 65. Cf. tambien: S. Benhabib, The Reluctant Modernism of Hannah Arendt, USA, Rowman \& Littlefield Publishers, 2000, 2003, pp. 132-133.

27 K. Marx, Grundrisse der Kritik der Politischen Ökonomie, citado en R. J. Berstein, Praxis y acción, traducido por G. Bello Reguera, Madrid, Alianza Editorial, 1979, p. 60. 
de la constante producción que preserva y fortalece la vida. En su consumación dialéctica, pues, la destrucción es "construcción" reiterada e incesante de la vida. La labor, al integrar el mundo a la vida, otorga a lo real la misma eternidad de la que goza la vida en sus ciclos: “( ...) consume productos para crear productos, o usa unos productos en cuanto medios de producción de otros" ${ }^{28}$. En este sentido, la realidad apuntada por Marx, poblada de laborantes que anulan constantemente la objetividad de lo ente, es un escenario en permanente construcción, una construcción incesante que nunca puede llegar a plasmar un estado de cosas estable, autónomo, duradero y enfrentado al sujeto.

La aproximación interpretativa de Arendt descubre una línea que conecta a Marx con la preocupación de los idealistas post-kantianos y, especialmente, con Hegel, una línea que, a pesar de los esfuerzos del filósofo de Tréveris por alejarse de la filosofía hegeliana, nunca dejó de unirlo a ésta. Descubre que el gran problema que enfrenta el comunismo en tanto doctrina "social" se identifica con el asumido por el idealismo en su forma especulativa: la otredad del mundo, el "carácter de cosa" de la realidad humanamente habitada. Debido a ello, tanto Hegel como Marx ponen todo su empeño filosófico en mostrar cómo el mundo ha de ser asumido como "sujeto", no como "objeto" frío, distante, autónomo. Al idealismo absoluto del pensador suabo se contrapone el "socialismo científico" del renano, pero no como una negación sin más, sino más bien como superación dialéctica. La realización marxiana de la filosofía es, según la filósofa alemana, una realización del hegelianismo, transformado en movimiento social emancipador.

Arendt no puede dejar de apartarse rotundamente de los principios hegeliano-marxianos que conceptualizan como amenaza el "carácter de cosa" del mundo, y dos de los epígrafes centrales de su La condición humana dan cuenta de su constante preocupación por ello: "El carácter de cosa del mundo" 29 y "El carácter duradero del mundo"30; es más, para ella, la condición fundamental para la existencia de una genuina política es el cuidado de la separación entre el hombre y su mundo, la conservación de la impenetrabilidad de éste con respecto a los impulsos, los deseos y la voracidad de la vida. De ahí su insistencia en la importancia de preservar las consecuencias "objetivadoras" del trabajo o la fabricación frente a su disolución en lo "líquido" de la labor. El mundo humano del sentido y de la acción dependen de esa producción que, al establecer límites infranqueables, al instituir la otredad y la extrañeza de un universo de cosas, permite la apertura de un espacio no colonizado por los requerimientos metabólicos y las exigencias puramente biológicas. De la insistencia en los procedimientos de la fabricación depende, en este sentido, la permanencia del mundo como hogar habitable y como espacio en el que actuar políticamente. Depende, en suma, que el ser humano no se abisme en el elemento indiferenciado de la nuda vida, en el que la política se torna imposible y comienza el reinado de la bio-política, es decir: el terror ${ }^{31}$.

En Marx, junto a su raigambre hegeliana, Arendt contempla la misma cualificación del "trabajo" como labor que es común a la Modernidad capitalista. El "trabajo"

\footnotetext{
K. Marx, El capital, I, op. cit., p. 223.

H. Arendt, La condición humana, op. cit., pp. 115-118.

Ibidem, pp. 165-167.

31 Para una interpretación de Arendt desde el concepto de biopolítica foucaltiano, cf. G. Agamben, Homo sacer. El poder soberano y la nuda vida, traducido por A. Gimeno Cuspinera, Valencia, Pre-textos, 1998.
} 
no es pensado como productor de cosas duraderas, sino como proceso de productividad inacabable. Aunque a veces parezca enfatizar en grado exagerado la correlación entre la economía política liberal y el pensamiento marxiano, el objeto de la filósofa es atender a una característica fundamental que, desde su perspectiva, no puede ser negada: la continuidad lógica entre el capitalismo y el comunismo, en tanto centrados en torno a la productividad indefinida de la labor. Por ello, “(...) Marx tenía toda la razón en un punto: el desarrollo lógico del capitalismo es el socialismo"32. Capitalismo y comunismo están "emparentados" 33 en la confianza en que, desaparecida la política, sólo dejará en su hueco la gestión de los recursos materiales.

El juicio de Arendt no puede ser más inequívoco: el humanismo marxiano se ordena en torno al principio anti-político del "hombre", al igual que el tronco principal de la tradición filosófica, siendo el mundo contemplado sólo como función de ese foco preeminente $\mathrm{y}$, en última instancia, obligado a desaparecer en él. Mientras la política es, para ella, preocupación por el mundo, la consistencia anti-política del filosofar nacido en Platón brilla de nuevo, con toda su potencia, en la obra del revolucionario alemán, preocupado exclusivamente por el sujeto: "Marx únicamente quería cambiar el mundo para liberar al hombre, para liberarlo del mundo" 34 . Frente a esto, Arendt enarbola una decidida defensa de la objetividad y el extrañamiento, de la reificación, de la diferencia de hombre y mundo, de la alienación en cierto sentido marxiano: los hombres no pueden fundirse con "el mundo", no pueden aspirar a reconocerse plenamente en él, so pena de perderse en los procesos interminables y carentes de libertad que guían el desarrollo de su acontecer natural; el mundo es, no la naturaleza asimilable, sino, precisamente, lo irreductible al organismo, aquello que no se puede integrar en las funciones orgánicas ni ha de desaparecer en ellas. El mundo, según Arendt, es lo sólido que posibilita la apertura de un lugar para la acción, no la materia que el organismo digiere para asegurar la propia pervivencia; el mundo no es, en suma, alimento para el cuerpo, sino lugar para la política. He aquí la gran distancia que media entre el concepto marxiano y el arendtiano de alienación: mientras la alienación marxiana se refiere a la relación del hombre con su propia actividad productiva, $y$, por lo tanto, sólo contempla el mundo como medio para la auto-apropiación efectiva del sujeto, en Arendt la alienación se refiere, precisamente, a la pérdida moderna del mundo como solidez estable y objetiva en la que es posible comenzar la efímera, incierta y frágil acción humana. Es la diferencia lo que, según Arendt, es preciso salvaguardar de los procesos naturales y orgánicos invasivos, porque es la diferencia - la presente entre la pluralidad de hombres, la que media también entre los hombres y el escenario mundano donde les es posible actuar- la que ofrece la posibilidad de un habitar político, pero no así la identidad entre ser humano y realidad, entre hombre y hombre ${ }^{35}$.

\footnotetext{
32 "Reunión con amigos y colegas en Toronto", en H. Arendt, Lo que quiero es comprender, traducido por M. Abella y J. L. López de Lizaga, Madrid, Editorial Trotta, 2010, p. 96.

33 Ibidem, p. 88.

34 "Documentos para el proyecto «Introducción a la política», en H. Arendt, ¿Qué es la política?, traducido por R. Sala Carbó, Barcelona, Paidós, 1997, p. 142.

35 “(...) en el discurso de Arendt se pierde identidad cuando decae la diferencia. En el discurso de Marx, por el contrario, la diferencia es el lugar de la alienación, y de la alienación se sale reconduciendo la diferencia a identidad, fundiendo al individuo en la comunidad reconciliada, en el género humano finalmente realizado como Uno". P. Flores D'Arcais, Hannah Arendt. Existencia y libertad, traducido por C. Cansino, Madrid, Tecnos, 1996, p. 71.
} 


\section{Evaluación crítica de la posición arendtiana en torno a Marx}

No es posible dejar de lado el hecho de que la crítica arendtiana a la confusión de trabajo y labor por parte de Marx ha sido duramente enjuiciada. Ya en 1962, desde la perspectiva de un humanismo marxista, Suchting se opuso a la interpretación general que Arendt ofreció en su La condición humana ${ }^{36}$. Según su artículo, la imagen de Marx ofrecida por la pensadora judía es "completamente errónea" ${ }^{37}$. De acuerdo con esto, el "trabajo" marxiano no se identifica en absoluto con la labor, dado que no puede ser considerado como la simple reproducción física del individuo: apunta, al contrario, más allá de la esfera de la producción estrictamente material, al desarrollo de las potencialidades humanas en su grado más elevado ${ }^{38}$. Por esta razón, para el autor, el papel de "profeta teórico" de la sociedad de laborantes que Arendt le adjudicó a Marx constituye, en su integridad, una falsedad ${ }^{39}$. En este respecto, sí parece claro que el juicio de Arendt contra Marx no hace del todo justicia a las palabras del filósofo alemán, ya que en él, el "trabajo", como afirma Cristina Sánchez, "es una actividad intencional y racional" es posible que el "trabajo" marxiano coincida en importantes aspectos con el trabajo -y no la labor- tal y como es en Arendt conceptualizado ${ }^{41}$. Arendt, según sus críticos, abstrae de su análisis un elemento cuya desaparición deforma gravemente la imagen resultante de la filosofía marxiana: para el pensador renano, existe una diferencia crucial entre dos tipos de "trabajo": el existente en el capitalismo, que es efectivamente una labor inmersa en las consecuencias de la alienación, y el apuntado en el proyecto de emancipación revolucionaria, que estaría libre de la alienación capitalista. Pues bien, tal y como expone Martin Jay ${ }^{42}$, que coincide en líneas generales con las críticas anteriores, en realidad Marx no pretendió superar toda forma de objetivación, como si ésta fuera por sí misma el elemento alienante del "trabajo", sino la específica forma de objetivación capitalista, intrínsecamente alienante. La objetivación es un momento esencial del trabajo marxiano, y es la reificación presente en sus formas alienadas aquello que requiere una superación ${ }^{43}$, ya que constituye una forma de trabajo regida por la necesidad externa y la utilidad ${ }^{44}$, una configuración de la actividad humana que se resuelve en la creación de "cosas" que sojuzgan, como poderes independientes y por medio de los mecanismos de mercado, a los trabajadores que las han producido. Por esta razón, también Bhikhu Parekh concluye en que la auténtica resolución de la concepción marxiana del campo de la actividad humana no

\footnotetext{
36 Cf. W. A. Suchting, "Marx and Hannah Arendt's The Human Condition”, Ethics, 73, 1962, pp. 47-55.

37 Cf. Ibidem, p. 47.

38 Cf. Ibidem, p. 51.

39 Cf. Ibidem, p. 52.

40 C. Sánchez, Hannah Arendt. El espacio de la politica, Madrid, Centro de Estudios Constitucionales, 2003, p. 151.

41 Cf. W. A. Suchting, "Marx and Hannah Arendt's The Human Condition", op. cit., p. 49.

42 M. Jay, "El existencialismo político de Hannah Arendt", en F. Birulés (comp.), Hannah Arendt: El orgullo de pensar, Barcelona, Gedisa, 2000, pp. 147-177.

43 Ibidem, p. 158. En esta misma dirección se manifiesta Tama Weisman en su estudio acerca de la posición de Arendt ante Marx: "Neither Hegelian nor Marxian labor merely relates labor to production for inmediate consumption. Labor is world building in the very same way as Arendtian work builds a world". Weisman, T., Hannah Arendt and Karl Marx. On Totalitarianism and the Tradition of Western Political Thought, Lanham-Boulder-New York-Toronto-Plymouth, UK, Lexington Books, 2014, p. 79.

44 Cf. W. A. Suchting, "Marx and Hannah Arendt's The Human Condition", op. cit., p. 52.
} 
es la conversión de todo trabajo en labor, sino, justamente, lo contrario: el horizonte de la revolución está gobernado por la conversión de toda labor alienante en trabajo, entendido éste en un sentido muy parecido al arendtiano ${ }^{45}$. Desde esta perspectiva, Marx, efectivamente, introduce una distinción no contemplada por Arendt, y la indiferencia de ésta ante ella compromete seriamente su análisis.

Si fuera cierto que Marx no postuló la inmersión humana en la labor, tal y como Arendt la entendió, ¿es por ello inválida la crítica de ésta al pensador renano? ¿Cabe deshacerse de ella como una crítica inadecuada y carente de plausibilidad? Admitiendo que Arendt no realizara una descripción atenta a los pliegues teóricos de la concepción marxiana, en lo que seguramente no estaba interesada, sí podemos advertir en su versión de la filosofía de Marx elementos que merecen ser señalados. En primer lugar, es importante al respecto, tal y como confiesa el mismo Martin Jay ${ }^{46}$, que esta interpretación no procede de la nada, sino, en primera instancia, del mismo campo del marxismo de Engels y la II Internacional ${ }^{47}$. Podemos subrayar, entonces, que existe en la crítica de Arendt una vinculación real a la historia efectual de la obra de Marx. Podríamos representarnos la aproximación de la pensadora judía, entonces, de otra manera, ya que su lectura de la obra de Marx vendría a perseguir aquello que pudo hacer posible la interpretación "ortodoxa" presentada en la II Internacional, y, más allá de ella, la del comunismo soviético. En realidad, Arendt no estaba tan interesada en lo que Marx efectivamente tenía como intención, sino en aquello que latía como supuesto en lo que dijo, aquello que, según sus análisis, contenía de hecho una posible interpretación de su filosofía en relación con los procesos capitales de la sociedad moderna. El verdadero objetivo de la crítica arendtiana, en consonancia con su interés por iluminar la radical novedad del totalitarismo y su problemática vinculación con la tradición de pensamiento político occidental, fue, antes que la posición adoptada por el mismo filósofo renano, su resonancia fatal en el marxismo posterior, y especialmente en sus versiones leninista y estalinista, que convirtieron definitivamente a la filosofía de Marx en poder político efectivo ${ }^{48}$. Contando con ello, Arendt construyó un "tipo ideal" de Marx, de acuerdo con el modo peculiar de comprender que la filósofa puso en ejercicio ${ }^{49}$. El Marx de Arendt, según esto, sería un tipo ideal en el que pulió, destacó y puso a la vista aquello que le pareció de real relevancia en relación con el significado que el marxismo cobró en el siglo XX; no es el filósofo objeto de un estudio académico y teórico riguroso y especializado, sino el Marx síntoma de la Modernidad, aquel en el que se manifiestan elementos decisivos de un pensamiento cargado de efectos. La pensadora alemana destacó en numerosas ocasiones cómo en el seno mismo del pensamiento marxiano latían multitud de con-

45 Cf. B. Parekh, "Hannah Arendt's Critique of Marx", en M. A. Hill (ed.), Hannah Arendt: The Recovery of the Public World, New York, Saint Martin’s Press, 1979, pp. 67-100.

46 M. Jay, "El existencialismo político de Hannah Arendt", op. cit., p. 157.

47 Para una exposición razonada acerca de la distancia que separa a esta interpretación del pensamiento efectivamente debido a Marx, cf. Ruiz Sanjuan, C., "Marx y el marxismo", Thémata. Revista de filosofia, 44, 2011, pp. 485-504. En este artículo se aclara convenientemente que “(...) aquello que suele entenderse bajo el rótulo de «materialismo dialéctico» dentro del marxismo tradicional responde en general a la posición de Engels, pero no a la de Marx". Ibidem, p. 488.

48 Weisman comparte esta postura: "Rather, she reads Marx as she believes Lenin and Stalin read him, and with what to her mind was more than adequate justification -justification that I will argue can be found in a particular reading of The Manifesto of the Communist Party". Weisman, T., op. cit. p. 65.

49 Acerca de la noción arendtiana de "tipo ideal", cf. H. Arendt, "Thinking and Moral Considerations", Social Research, 38:3, 1971, pp. 417-446. 
tradicciones, y trató de poner en claro, antes que cualquier otra cosa, el significado efectivo que en el mundo moderno llegó a poseer la propuesta que bajo ellas se afianzó como positiva. La lectura arendtiana de Marx es una lectura interesada, en el sentido pleno de la palabra: interesada en hallar el auténtico núcleo significativo que convirtió a la filosofía de Marx en crucial para la historia del pensamiento y la práctica política posteriores. Con todo ello, podemos afirmar que, aunque no fuera fiel a todas las indicaciones contenidas en la obra del filósofo alemán, su lectura está articulada por una legítima caracterización del significado general que alcanzó a poseer. Un tipo ideal, comprendido a la manera de Arendt, no es una construcción caprichosa, sino guiada por un interés de comprensión que se prueba en la capacidad de iluminar los fenómenos; de acuerdo con ella, la imagen de Marx que procuró componer poseía esa cualidad iluminadora que permitía comprender cómo la recepción del filósofo estuvo marcada por ciertas constantes de relevancia crucial para el devenir de la política y la sociedad contemporáneas.

Para terminar, cabría destacar cómo la interpretación arendtiana de Marx posee justificación suficiente si la ponemos en contacto con algunos de los problemas presentes en la obra de éste, con la propia teoría de Arendt acerca del lugar del ser humano en relación a la naturaleza y al trabajo, $\mathrm{y}$, por último, con las intuiciones de Simone Weil acerca de la naturaleza del marxismo:

a. En primer lugar, si fuera cierto que Marx hubiera apuntado efectivamente a una superación de la labor alienante y formulado, así, una concepción del "trabajo" afín a la de Arendt, también lo es que tendió a vincular tal capacidad humana a la naturaleza. Ya hemos citado cómo, para él, el "trabajo" es entendido como metabolismo del hombre con la naturaleza, “(...) no es más que la manifestación de una fuerza natural, de la fuerza de trabajo del hombre" Esta afirmación supone, desde la perspectiva de Arendt, una constante suficiente, dado que se repite desde sus primeros escritos no publicados hasta $E l$ capital $^{51}$. La cuestión central en este respecto es si, considerado como "fuerza natural", el "trabajo" puede adquirir realmente cualidades distintas a las de la labor arendtiana. Según la teoría de la autora, el trabajo - creador del mundo humano- no posee continuidad con la naturaleza y supone el trazado de un corte o diferencia determinante con respecto a toda fuerza o impulso natural. En eso radica su distinción con respecto a la labor. Por eso, a diferencia de ésta, puede producir "objetos" ontológicamente diferenciados. Marx, al conceptualizar todo "trabajo" como manifestación natural del ser humano, al insertarlo en el sistema de las realidades naturales, podría estar, de hecho, condenando a todo "trabajo" a ser labor, aparte de que él tuviera la intención de liberar al hombre del dominio de ésta; aunque persiguiera, de hecho, la conversión de la labor (alienada) en genuino trabajo, tal y como defiende Parekh $^{52}$, la base

50 K. Marx, "Glosas marginales al programa del Partido Obrero Alemán”, en F. Engels y K. Marx, Crítica del Programa de Gotha. Crítica del Programa de Erfurt, traducido por Grupo de traductores de la Fundación Federico Engels, Madrid, Fundación Federico Engels, 2004, p. 23.

51 En los Manuscritos puede apreciarse también la cualidad metabólica de la relación entre ser humano y naturaleza: "La naturaleza es el cuerpo inorgánico del hombre". K. Marx y E. Fromm, Marx y su concepto del hombre. Manuscritos económico-filosóficos, op. cit., p. 110. Este carácter es confirmado por Marx en otros textos posteriores. En lo concerniente a El capital, cf. nota 18.

52 Cf., supra, p. 18. 
sobre la que construyó su concepción parece forzarle, como afirma Arendt, a asumir toda actividad humana como labor $^{53}$.

b. En segundo lugar, si nos acercamos a los medios con los que Marx pretendió la emancipación de los trabajadores, también podemos advertir que, partiendo de la conceptualización arendtiana, él mismo se condenó a fijar la actividad creativa del hombre a las cadenas de la labor. Una y otra vez el filósofo alemán repite que no hay marcha atrás en el desarrollo de las fuerzas productivas, y que la liberación del "trabajo" humano de sus estructuras cosificantes no puede provenir de un cese de las condiciones modernas de producción, sino de su intensificación y desarrollo plenos. El hiato que encontramos, entonces, afecta al modo en que los medios de producción modernos, que habían sujetado a los trabajadores al desarrollo de actividades intrínsecamente alienantes -como las desarrolladas en los procesos automatizados- podrían por sí mismos convertirse en medios de emancipación. ¿No es la desarrollada en la industria, con sus modos de producción específicos, una actividad ineludiblemente laborante? En este sentido, el que la propiedad sea de uno, de varios o de todos, como se pudo advertir en la realidad industrial soviética, no afecta, en absoluto, a la actividad en sí misma, así como tampoco lo hace la distribución efectiva de su producto. Tal y como pensó Weil, en tantos aspectos cercana al pensamiento de Arendt, "si se acepta la cultura industrialista, aunque con otra forma de apropiación de los medios de producción, sólo se puede organizar y perfeccionar la opresión, no aliviarla"54.

En ambos casos (a) y (b), nos encontraríamos, en definitiva, con una imposibilidad localizada en el núcleo de la filosofía marxiana, una imposibilidad decisiva que, a pesar del ánimo emancipador del filósofo, impediría radicalmente la efectiva distinción de labor y trabajo. Marx se enfrentaría a su propia impotencia, a su incapacidad para dejar atrás las categorías productivistas de la metafísica occidental ${ }^{55}$. Aunque su perspicaz mirada a la sociedad moderna haya, efectivamente, observado los elementos de la opresión humana, como en muchos casos hizo, le faltó la audacia conceptual necesaria para dibujar una efectiva salida de los fundamentos sobre los que históricamente se levantó. Acudiendo de nuevo al texto de Weil citado más arriba,

Marx (...) analiza y desmonta con claridad admirable el mecanismo de la opresión capitalista; pero da cuenta de todo ello tan bien, que no se puede imaginar cómo, con los mismos engranajes, el mecanismo podría un buen día transformarse $(. . .)^{56}$.

53 Contra esta interpretación del "trabajo" marxiano como puro intercambio fisiológico-natural entre ser humano y naturaleza, puede ser provechosa la aportación de M. Heinrich, quien basándose en la distinción entre trabajo concreto y abstracto critica a los que ofrecen, como hace Arendt, una interpretación puramente naturalista de la concepción marxiana. Cf. M. Heinrich, Crítica de la economía política. Una introducción a El Capital de Marx, traducido por C. Ruiz Sanjuán, Madrid, Escolar y Mayo, 2008.

54 F. Fernández Buey, "Prólogo", en S. Weil, Escritos históricos y políticos, traducido por A. López y M. Tabuyo, Madrid, Editorial Trotta, 2007, p. 23.

55 Ramas San Miguel expresa la posición de Arendt como sigue: “(...) en el espacio de lo que podría llamarse una metafísica de la historia y de la vida es estructuralmente imposible dejar lugar a lo que él mismo [Marx] por otro lado desearía salvar: el espacio de lo político y la libertad". C. Ramas San Miguel, "Pensar al borde de la tradición. La lectura arendtiana de Marx", Res Publica. Revista de Historia de las Ideas Políticas, 18, № 1, 2015, pp. 75-94, aquí p. 90.

56 "Sobre las contradicciones del marxismo", en S. Weil, op. cit., p. 128. 